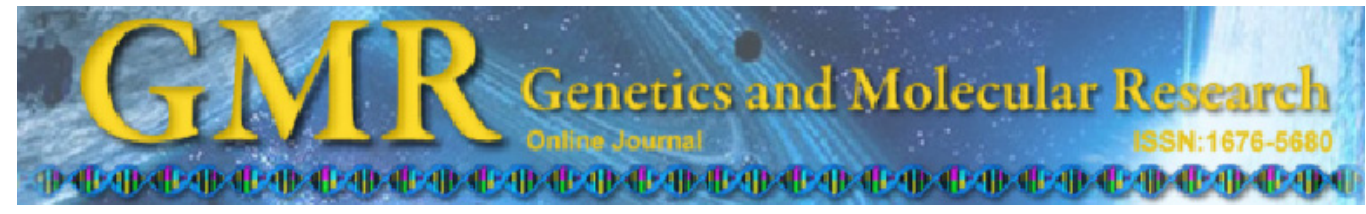

\title{
Association of RGA-SSCP markers with resistance to downy mildew and anthracnose in grapevines
}

\author{
P.A. Tantasawat ${ }^{1,2}$, O. Poolsawat ${ }^{1,2}$, T. Prajongjai ${ }^{1}$, W. Chaowiset $^{1}$ and \\ A. Tharapreuksapong ${ }^{1}$
}

${ }^{1}$ Suranaree University of Technology, Nakhon Ratchasima, Thailand ${ }^{2}$ Center of Excellence on Agricultural Biotechnology (AG-BIO/PERDO-CHE), Bangkok, Thailand

Corresponding author: P.A. Tantasawat

E-mail: piyada@sut.ac.th

Genet. Mol. Res. 11 (3): 1799-1809 (2012)

Received March 1, 2012

Accepted June 5, 2012

Published July 2, 2012

DOI http://dx.doi.org/10.4238/2012.July.2.1

\begin{abstract}
Downy mildew (Plasmopara viticola) and anthracnose (Sphaceloma ampelinum) are two major diseases that severely affect most grapevine (Vitis vinifera) cultivars grown commercially in Thailand. Progress of conventional breeding programs of grapevine for improved resistance to these diseases can be speeded up by selection of molecular markers associated with resistance traits. We evaluated the association between 13 resistance gene analog (RGA)-single-strand conformation polymorphism (SSCP) markers with resistance to downy mildew and anthracnose in 71 segregating progenies of seven cross combinations between susceptible cultivars and resistant lines. $F_{1}$ hybrids from each cross were assessed for resistance to downy mildew and anthracnose (isolates Nk4-1 and Rc2-1) under laboratory conditions. Association of resistance traits with RGA-SSCP markers was evaluated using simple linear regression analysis. Three RGA-SSCP markers were found to be significantly correlated with anthracnose resistance, whereas significant correlation with downy mildew resistance was observed for only one RGA-SSCP marker. These results demonstrate the usefulness of RGASSCP markers. Four candidate markers with significant associations
\end{abstract}


to resistance to these two major diseases of grapevine were identified. However, these putative associations between markers and resistance need to be verified with larger segregating populations before they can be used for marker-assisted selection.

Key words: Plasmopara viticola; Resistance gene analog; Vitis spp; Single-strand conformation polymorphism; Sphaceloma ampelinum

\section{INTRODUCTION}

Grapevine (Vitis spp) is one of the economic fruit crops that grow well in tropical areas, including Thailand. However, its cultivation has been limited by high costs associated with disease and insect management. Downy mildew (Plasmopara viticola) is the most destructive fungal disease affecting grapevine in Thailand, followed by anthracnose (or scab as called by Thai pathologists [Sphaceloma ampelinum; teleomorph Elsinoë ampelina]). These diseases can cause as high as 50\% crop losses in a season (CAB International, 2000). The application of fungicides to control diseases is efficient, but expensive and harmful to users and consumers. Thus, conventional breeding for disease resistance has been frequently employed, using American and Asian cultivars or wild species as sources of resistance in many countries including United States, China and Thailand (Reisch and Pratt, 1996; Mahanil, 2007; Tian et al., 2008; Louime et al., 2011). However, the phenotypic selection used in conventional breeding may be complicated by the genotype-environment interactions, epistasis, and difficult, unreliable, time-consuming, or expensive testing procedures. Therefore, selection at the DNA level for markers closely linked to the traits of interest, such as productivity, resistance and quality, should be more efficient, enabling the evaluation of a large number of plants in a time- and cost-effective manner. Moreover, marker-assisted selection allows breeders to make sophisticated decisions in choosing appropriate parents and screening desirable progeny at an early stage. In addition, disease and insect resistance traits can be selected in the absence of pests using this approach (Shalini et al., 2007; Collard and Mackill, 2008).

Several molecular marker systems such as random amplified polymorphic DNA (RAPD), restriction fragment length polymorphism (RFLP), amplified fragment length polymorphism (AFLP), simple sequence repeat (SSR), inter-simple sequence repeat (ISSR), and single-strand conformation polymorphism (SSCP) have been used in the analysis of marker-trait association (Roy et al., 2006; Wang et al., 2010; Bandyopadhyay, 2011; Diaz et al., 2011; Immanuel et al., 2011; Kalivas et al., 2011; Milad et al., 2011; Nisar and Ghafoor, 2011; Yu et al., 2011). The association of these molecular markers with different traits related to disease and insect resistance has been established in several plants (Lefebvre and Chèvre, 1995; Obert et al., 2000; Shalini et al., 2007). In grapevine, molecular markers for resistance against powdery mildew, downy mildew, Pierce's disease, and dagger nematode have also been discovered (Delmotte et al., 2006; Mahanil, 2007; Riaz et al., 2009, 2011; Adam-Blondon et al., 2011). However, when three RAPD markers reported to be linked to anthracnose resistance in Chinese wild grapes (Wang X et al., 2000; Wang Y et al., 2000; Zhang et al., 2001) were evaluated in 7 cross combinations of grapevine in Thailand, there was either no polymorphism between susceptible and resistant parents or no significant association between the marker and anthracnose resistance (Poolsawat, 2010). Similarly, no 
polymorphism was found between four susceptible parents and four resistant parents, when three resistance gene analog (RGA)-sequence-tagged site (STS) markers previously reported to be linked to downy mildew resistance in the 'Horizon x Illinois 547-1' cross (Mahanil et al., 2007) were evaluated (Prajongjai T, Wongkaew S and Tantasawat PA, unpublished data). Therefore, the successful utilization of these markers may be limited to only certain populations resulting from crosses between specific parents, possibly due to the large and diverse repertoire of resistance genes (R genes) present in different resistance sources. To overcome this limitation and as an alternative to using planned cross populations $\left(\mathrm{F}_{1} \mathrm{~s}, \mathrm{~F}_{2} \mathrm{~s}, \mathrm{BCs}\right.$, RILs, etc.), which may require substantial time and labor to develop, the association of molecular markers with traits has been identified through the utilization of germplasm segregating for the traits of interest and the regression analysis (Pradeep et al., 2007; Abdurakhmonov and Abdukarimov, 2008; Adam-Blondon et al., 2011). This approach offers an appealing ability to explore the associations between markers and $\mathrm{R}$ genes in a larger set of resistant genotypes varying in genetic background of $\mathrm{R}$ genes, and should allow a rapid and efficient survey of marker-R gene associations in multiple cross combinations involving different resistant parents.

The ability of SSCP markers to detect a single base pair change in the DNA sequence rapidly and inexpensively makes them highly efficient for analyzing genetic diversity and relationships as well as for marker-trait association (Cai and Touitou, 1993; Sunnucks et al., 2000). In this study, SSCP primers were designed from RGAs of two grapevine genotypes resistant ('NY88.0507.01') and susceptible ('Black Queen') to downy mildew and anthracnose (Seehalak et al., 2011). The potential use of these RGA-SSCP markers in the detection of downy mildew and anthracnose resistance genes was then evaluated in segregating populations of grapevine $\mathrm{F}_{1}$ hybrids from seven different cross combinations using regression analysis.

\section{MATERIAL AND METHODS}

\section{Plant materials}

$\mathrm{F}_{1}$ hybrids from seven crosses of grapevine between two female parents, showing high fruit quality but susceptibility to downy mildew and anthracnose ('Black Queen' and 'Carolina Black Rose'), and four resistant male parents, which are complex interspecific hybrids, 'Wilcox 321' (Blue Jay (V. riparia x V. labrusca) x MN 242), 'NY88.0517.01' (Joannes Seyve $23.416 \times(V$. rupestris $\times$ V. cinerea)), 'NY65.0550.04' ((Jaeger 70 ( $V$. rupestris $\times$ V. lincecumii) x Victoria's Choice) x (Seyve Villard 23-18 selfed)), and 'NY65.0551.05' ((Jaeger 70 ( $V$. rupestris x V. lincecumii) x Victoria's Choice) x Lady Patricia (S.14664' x S.V. 20-365')), were used in this experiment. The resistant male parents were obtained from the grape breeding programs at New York State Agricultural Experiment Station (NYSAES), Cornell University, NY, USA. They had variable levels of genetic background from several American species such as $V$. cinerea, $V$. riparia, $V$. rupestris, $V$. labrusca, and $V$. lincecumii, along with $V$. vinifera in their pedigrees, and were selected based on field observations for downy mildew and/or anthracnose resistance. In total, $71 \mathrm{~F}_{1}$ hybrids from seven crosses including 'Black Queen x Wilcox 321' (12 hybrids), 'Black Queen x NY88.0517.01' (12 hybrids), 'Black Queen x NY65.0550.04' (9 hybrids), 'Black Queen x NY65.0551.05' (9 hybrids), 'Carolina Black Rose x NY88.0517.01' (10 hybrids), 'Carolina Black Rose x NY65.0550.04' (9 hybrids), and 'Carolina Black Rose $x$ NY65.0551.05' (10 hybrids) were used for the association analysis. 
The $\mathrm{F}_{1}$ seedlings were grown in a greenhouse in 24-cm diameter $\mathrm{x} 20$-cm deep plastic pots in a soil mix (peat moss, soil, burnt rice-chaff, perlite, vermiculite, and sand in a 1:1:1/2:1: 1:3/4 ratio by volume) with one plant per pot. The plants were protected from diseases by spraying once every 2 weeks with $2 \mathrm{~g} / \mathrm{L}$ mancozeb (manganese ethylenebis [dithiocarbamate]) and $0.6 \mathrm{~g} / \mathrm{L}$ triadimefon (1-(4-chlorophenoxy)-3,3-dimethyl-1-(1H-1,2,4-triazol-1-yl) butanone) for disease management. Plants were fertilized with $10 \mathrm{~mL} / \mathrm{L}$ 11-8-6 foliar fertilizer every 2 weeks, and stable manure was applied every 2 months. The fungicides were exempted for 1 month prior to inoculation.

\section{Downy mildew resistance evaluation}

$\mathrm{F}_{1}$ hybrids of seven crosses were evaluated for resistance to downy mildew by detached leaf assay as described by Mahanil (2007). The number of total spores per leaf was determined and converted to number of spores $/ 25-\mathrm{cm}^{2}$ leaf area. Resistance levels were classified into 6 classes based on spore production: $0=0-5$ spores $/ 25 \mathrm{~cm}^{2} ; 1=6-10$ spores $/ 25 \mathrm{~cm}^{2} ; 2$ $=11-15$ spores $/ 25 \mathrm{~cm}^{2} ; 3=16-25$ spores $/ 25 \mathrm{~cm}^{2} ; 4=26-40$ spores $/ 25 \mathrm{~cm}^{2} ; 5=\geq 40$ spores $/ 25$ $\mathrm{cm}^{2}$. Data recorded for disease reaction were transformed using $X^{\prime}=(X+1)^{1 / 2}$.

\section{Anthracnose resistance evaluation}

$\mathrm{F}_{1}$ hybrids of seven crosses were assessed for anthracnose resistance by the excised leaf assay described by Tharapreuksapong et al. (2009). Two S. ampelinum singleconidial isolates from Nakhon Ratchasima (Nk4-1) and Ratchaburi (Rc2-1) Provinces as described by Poolsawat et al. (2009) were used for the analysis. The disease severity was estimated by lesion score (a scale of 1 to 5 based on lesion numbers per inoculated droplet: $1=0-6$ lesions; $2=7-25$ lesions; $3=26-50$ lesions; $4=51-100$ lesions; $5=\geq 100$ lesions) (Poolsawat et al., 2012). Disease severity value of each hybrid was transformed using $X^{\prime}=(X+1)^{1 / 2}$.

\section{DNA extraction, primer design and restriction enzyme selection}

The genomic DNA of $F_{1}$ hybrids was extracted by the cetyltrimethylammonium bromide (CTAB) method according to Owens (2003) and dissolved in sterile deionized water at a concentration of $30 \mathrm{ng} / \mu \mathrm{L}$. The concentration and purity of DNA were determined using an ND-1000 spectrophotometer (NanoDrop Technologies Inc., Wilmington, DE, USA) at $\mathrm{A}_{260}$ and $\mathrm{A}_{280}$. Six specific SSCP primer pairs were designed from the sequences of grapevine RGAs derived from genomic DNA of a downy mildew and anthracnose-resistant hybrid 'NY88.0507.01' (rgVhybNY507_11, rgVhybNY507_17, rgVhybNY507_28, rgVhybNY507_90, and rgVhybNY507_92) and a susceptible cultivar 'Black Queen' (rgVvinBQ_47) (Seehalak et al., 2011) by using Primer 3 (v. 0.4.0; http://frodo.wi.mit.edu/ primer3/), and were named after their respective RGA clones. The similarity of these RGAs to other genes/proteins at the levels of nucleotide and amino acid sequences is summarized in Table 1. Appropriate restriction enzymes that cut each RGA into ca. 100- to 200-bp DNA fragments were selected from NEBcutter V2.0 (http://tools.neb.com/NEBcutter2/). 
RGA-SSCP markers associated with grapevine disease resistance

1803

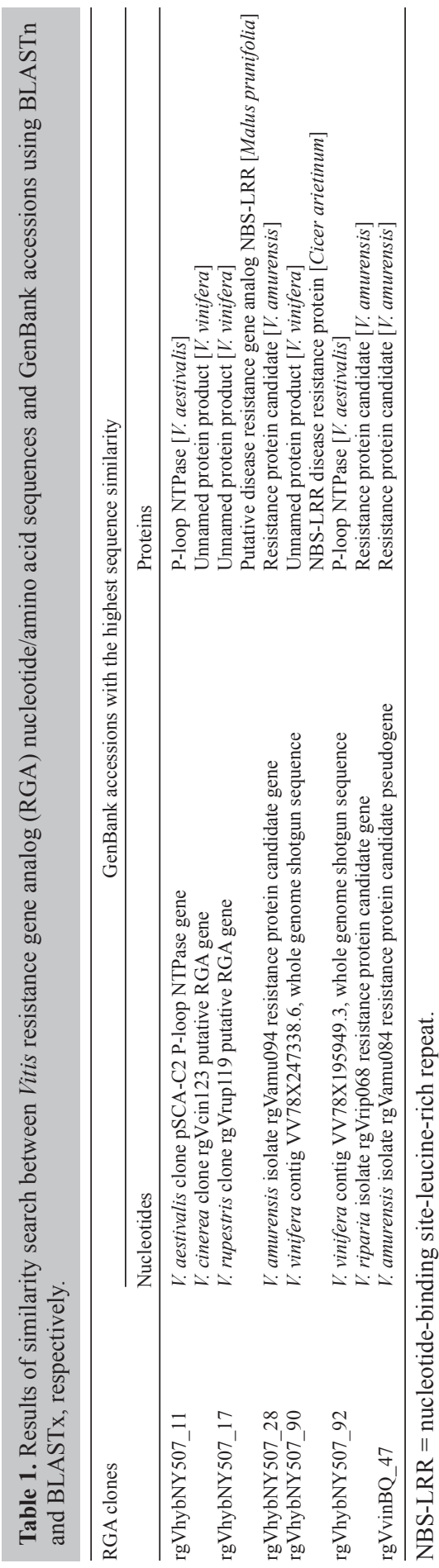




\section{SSCP analysis}

Each $20-\mu \mathrm{L}$ PCR mix contained $30 \mathrm{ng}$ genomic DNA template, $1 \mathrm{X}$ buffer $[75 \mathrm{mM}$ Tris$\left.\mathrm{HCl}, \mathrm{pH} 9.0,50 \mathrm{mM} \mathrm{KCl}, 20 \mathrm{mM}\left(\mathrm{NH}_{4}\right)_{2} \mathrm{SO}_{4}\right], 0.1 \mathrm{mM}$ of each dNTPs, $2.5 \mathrm{mM} \mathrm{MgCl}, 2 \mu \mathrm{M}$ RGA-SSCP primers (Table 2) and 1 U Taq DNA polymerase (Invitrogen, Brazil). The conditions for PCR in a ThermoHybaid Px2 thermocycler (Thermo Fisher Scientific, Inc., Waltham, MA, USA) were as follows: denaturation at $94^{\circ} \mathrm{C}$ for $5 \mathrm{~min} ; 25-40$ cycles of denaturation at $92^{\circ} \mathrm{C}$ for $50 \mathrm{~s}$, annealing at $45-63^{\circ} \mathrm{C}$ for $50 \mathrm{~s}$, extension at $72^{\circ} \mathrm{C}$ for $1 \mathrm{~min}$, and a final extension at $72^{\circ} \mathrm{C}$ for $10 \mathrm{~min}$. Briefly, the PCR products amplified by each primer pair were cut by a selected restriction enzyme (Table 2). The restricted PCR products $(6 \mu \mathrm{L})$ were diluted with 3 $\mu \mathrm{L} 3 \mathrm{X}$ SSCP loading dye $[95 \%(\mathrm{v} / \mathrm{v})$ formamide, $0.05 \%(\mathrm{w} / \mathrm{v})$ xylene cyanol, $0.05 \%(\mathrm{w} / \mathrm{v})$ bromophenol blue, and $20 \mathrm{mM}$ EDTA, $\mathrm{pH} 8.0]$ and denatured at $94^{\circ} \mathrm{C}$ for $5 \mathrm{~min}$. The samples were then immediately cooled on ice before loading. Electrophoresis was performed on an $8 \%(\mathrm{v} / \mathrm{v})$ polyacrylamide gel [acrylamide/bis, 19:1, 2\% (v/v) glycerol, 1X TBE, 0.10\% (v/v) TEMED, and $0.01 \%(\mathrm{w} / \mathrm{v})$ ammonium persulfate] at $4{ }^{\circ} \mathrm{C}, 200 \mathrm{~V}$ for $60 \mathrm{~min}$. The gel was stained with silver nitrate according to Sambrook and Russell (2001). The DNA bands on all the gels were scored in a matrix with the absence of amplification product as " 0 " and the presence as " 1 " and used in a simple linear regression analysis with phenotypic data of downy mildew and anthracnose resistance evaluations on each of the seven crosses. SSCP analysis was performed 2-5 times and only the reproducible DNA bands were scored.

\begin{tabular}{|c|c|c|c|c|}
\hline Primers* & Primer sequence $\left(5^{\prime}-3^{\prime}\right)$ & Annealing temperature $\left({ }^{\circ} \mathrm{C}\right)$ & Restriction enzyme & PCR product size (bp) \\
\hline \multirow[t]{2}{*}{ rgVvinBQ_47 } & F: CATTCAAAAATCGCGTTGTA & 63 & $A l u \mathrm{I}$ & 77 \\
\hline & R: GAAATGGTTCTCCGTCAGTG & & & 137 \\
\hline \multirow[t]{2}{*}{ rgVhybNY507_11 } & F: AGTTGAACAGCTTCCCCTGT & 45 & ApoI & 123 \\
\hline & R: TCCGAAAACTGAGGTTTGCT & & & 193 \\
\hline \multirow[t]{2}{*}{ rgVhybNY507_17 } & F: TCTCCCTGCTTTCCTGCCAAAC & 58 & EcoRI & 160 \\
\hline & R: GGTGGGTGCAAATGCTCACAGA & & & 306 \\
\hline \multirow[t]{2}{*}{ rgVhybNY507_28 } & F: GAGGCCATTAGCATCCTCTA & 50 & MboII & 100 \\
\hline & R: GATTGGTAGCAGGCAAAAAG & & & 110 \\
\hline \multirow[t]{2}{*}{ rgVhybNY507_90 } & F: TCTCCGTCCCTAATTTCTCC & 58 & TaqI & 180 \\
\hline & R: CGTAATTTCCTGAGCACCAA & & & 94 \\
\hline \multirow[t]{2}{*}{ rgVhybNY507_92 } & F: GGAGGCCGTCACACTCTTTG & 62 & $\operatorname{HinfI}$ & 268 \\
\hline & R: GGTTGGGTTGACGCAGTGAT & & & 166 \\
\hline
\end{tabular}

*Primers were named according to their respective RGAs.

\section{Statistical analysis}

The association between RGA-SSCP markers and disease resistance was evaluated by simple linear regression analysis using the SPSS version 14.0 program (Levesque and SPSS Inc., 2006) where each resistance trait was treated as a dependent variable, while the RGASSCP marker was treated as an independent variable (Virk et al., 1996). $\mathrm{R}^{2}$ denotes the square of $r$, the correlation coefficient. Each marker was calculated for beta statistics, which is defined as standardized regression coefficient $=B S x / S y$, where $B$ is the regression coefficient and $S x$ and $S y$ are the standard deviations of the independent $(x)$ and dependent $(y)$ variables (Kar et al., 2008; Ruan et al., 2009). The association of markers with disease resistance was assessed by testing the level of significance using the Student $t$-test. 


\section{RESULTS AND DISCUSSION}

Genetic association of downy mildew and anthracnose resistance with RGA-SSCP markers (designed from five RGAs of a resistant hybrid 'NY88.0507.01' and one RGA from a susceptible cultivar 'Black Queen') was evaluated in segregating populations of 71 grapevine $\mathrm{F}_{1}$ hybrids from seven cross combinations. In each of the seven crosses examined, one to three RGA-SSCP primer pairs were able to generate polymorphic DNA bands between resistant and susceptible parents. In total, 13 RGA-SSCP markers were found to be polymorphic, including BQ47_1, BQ47_2, BQ47_3, NY11_1, NY17_1, NY28_1, NY28_2, NY28_3, NY90_1, NY92_1, NY92_2, NY92_3, and NY92_4, which were amplified by primers rgVvinBQ_47, rgVhybNY507_11, rgVhybNY507_17, rgVhybNY507_28, rgVhybNY507_90, and rgVhybNY507_92, respectively. Simple linear regression analysis was performed to determine the association of these RGA-SSCP markers with downy mildew and anthracnose resistance. Phenotypic values of each of the three resistance traits (downy mildew resistance and anthracnose resistance to isolates Nk4-1 and Rc2-1) were separately regressed on each of the polymorphic markers. A summary of simple linear regression, beta, $t$-test, and $\mathrm{R}^{2}$ for downy mildew and anthracnose resistance is shown in Table 3. Four of 13 polymorphic RGA-SSCP markers were found to be associated with downy mildew or anthracnose resistance. Among these markers, one marker (NY28_1) was linked to downy mildew resistance and three markers (NY92_1-3) were linked to anthracnose resistance. Figures 1 and 2 show RGA-SSCP profiles generated with RGA-SSCP primers rgVhybNY507_28 and rgVhybNY507_92, respectively. The NY28_1 marker showed a negative correlation $\left(\mathrm{R}^{2}=0.522\right)$ with downy mildew resistance in the "Carolina Black Rose x NY65.0550.04' cross. This marker showed significant $(t=-2.765, \mathrm{P}=$ $0.028)$ and high standardized beta coefficient $(-0.722)$, suggesting that it was associated with downy mildew resistance.

Because anthracnose resistance has been shown to be isolate-specific in grapevine (Poolsawat et al., 2010), two virulent anthracnose isolates (Nk4-1 and Rc2-1), which differ genetically, were used for the disease response evaluation. The association of RGA-SSCP markers with resistance to both isolates of anthracnose is presented in Table 3. In case of resistance to anthracnose isolate Nk4-1, two markers (NY92_1 and NY92_3) were identified through simple linear regression analysis. Beta coefficients and $t$ values revealed that they were highly significant (NY92_1; $t=4.776, \mathrm{P}=0.003)$ and significant (NY92_3; $t=$ $2.906, \mathrm{P}=0.027)$. They showed a positive correlation with resistance to anthracnose isolate Nk4-1 with $\mathrm{R}^{2}$ values of 0.792 and 0.585 , respectively, in the 'Carolina Black Rose $\mathrm{x}$ NY65.0550.04' cross. Hence, these markers were associated with susceptibility to anthracnose isolate Nk4-1. It is interesting to note that NY92_3 was highly correlated with NY92_1 $(\mathrm{r}=0.745 ; \mathrm{P}=0.017)$, suggesting that selection based on only NY92_1, which exhibited the highest $\mathrm{R}^{2}$, should be sufficient. Anthracnose resistance to isolate $\bar{R} \mathrm{c} 2-1$ was found to be associated with the marker NY92_2. This marker showed negative and significant correlation $\left(\mathrm{R}^{2}=0.638 ; t=-3.249, \mathrm{P}=0.01 \overline{7}\right)$ in the 'Black Queen $\mathrm{x}$ NY65.0550.04' cross, and high standardized beta coefficient of -0.799 . These results indicate that NY92_2 showed a strong association with anthracnose resistance to isolate Rc2-1. It appears that the resistance to both isolates of anthracnose can be identified by SSCP analysis using only the rgVhybNY507_92 primer pair and HinfI (Table 2). 
P.A. Tantasawat et al.

1806

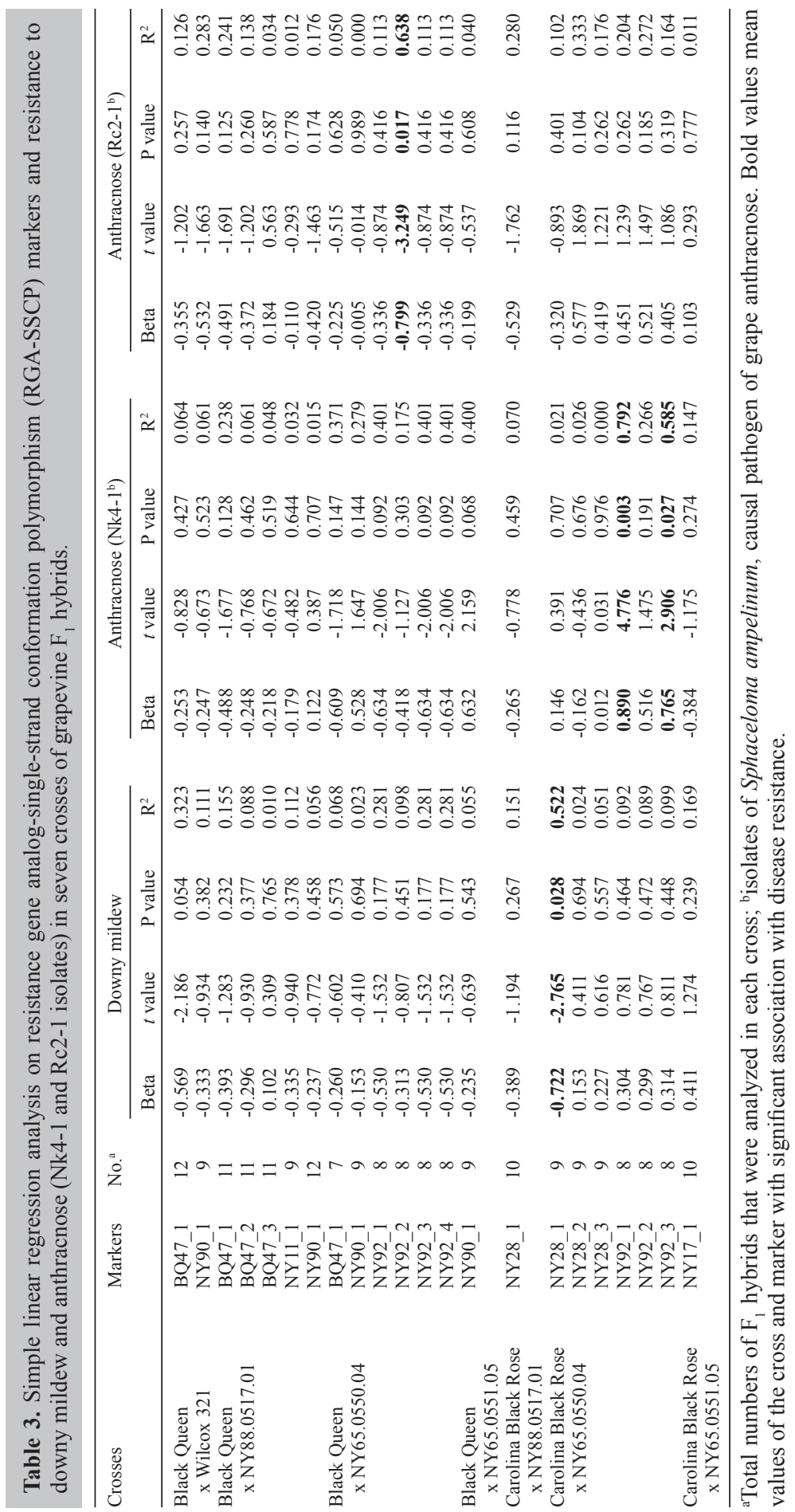




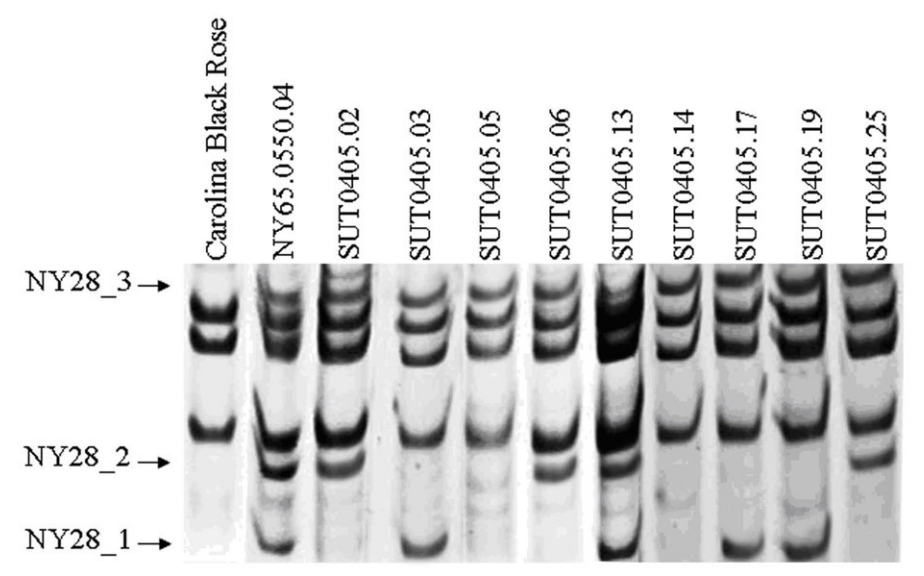

Figure 1. Electrophoretic patterns of amplified and restricted fragments generated from $9 F_{1}$ hybrids and both parents of the 'Carolina Black Rose x NY65.0550.04' cross with resistance gene analog-single-strand conformation polymorphism primer rgVhybNY507_28 and MboII on 8\% polyacrylamide gel.

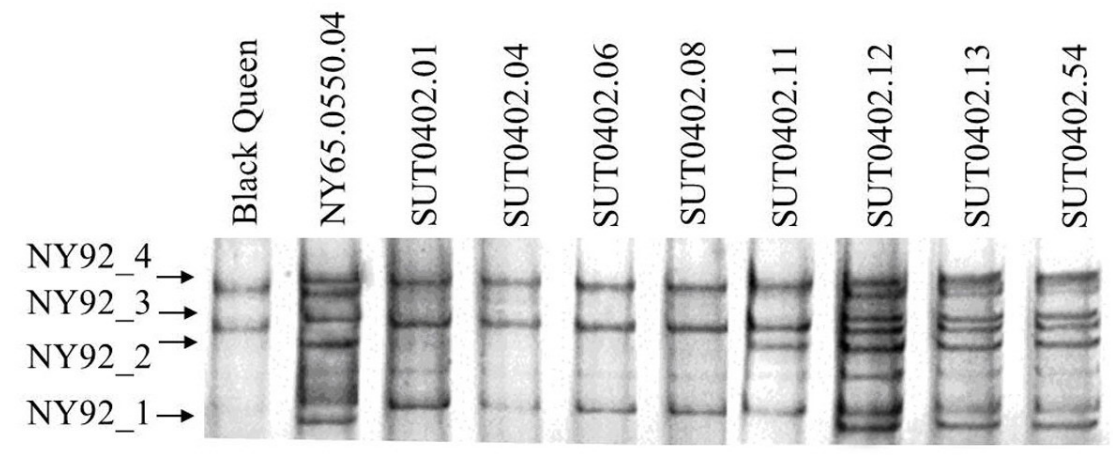

Figure 2. Electrophoretic patterns of amplified and restricted fragments generated from $8 \mathrm{~F}_{1}$ hybrids and both parents of the 'Black Queen x NY65.0550.04' cross with resistance gene analog-single-strand conformation polymorphism primer rgVhybNY507_92 and HinfI on 8\% polyacrylamide gel.

These results suggest that RGA-SSCP markers are efficient for the assessment of downy mildew and anthracnose resistance in grapevine at an early stage. Downy mildew resistance and anthracnose resistance to Nk4-1 and Rc2-1 isolates can be identified by 3 RGASSCP markers, NY28_1, NY92_1 and NY92_2, with the percentage of phenotypic variance explained by each marker $\left(\mathrm{R}^{2}\right)$ of $52.2,79.2$ and $63.8 \%$, respectively. In addition, these results indicate that the associations between all three RGA-SSCP markers with downy mildew or anthracnose resistance were found in cross combinations with 'NY65.0550.04' as a male parent. V. champini, V. rupestris, V. simpsoni, V. shuttleworthii, V. labrusca, V. smalliana, V. rotundifolia, V. tiliafolia, $V$. vulpina, $V$. munsoniana, etc., have been reported as sources of resistance to anthracnose (Mortensen, 1981), while downy mildew resistance can be found in $V$. amurensis, V. cinerea, V. labrusca, V. rotundifolia, V. riparia, V. rupestris, etc. (Reisch and Pratt, 1996; Brown and Moore, 1999). It should be noted that $V$. rupestris, $V$. lincecumii, $V$. labrusca, and V. riparia are progenitors of 'NY65.0550.04'. The highly significant and significant general 
combining ability values of 'NY65.0550.04' for anthracnose and downy mildew resistance, respectively, suggest that it is a good parent for breeding programs to improve anthracnose and downy mildew resistance of grapevine in Thailand. In particular, the 'Carolina Black Rose $\mathrm{x}$ NY65.0550.04' cross is recommended for improvement of both downy mildew and anthracnose resistance (Mahanil, 2007; Poolsawat O, Wongkaew S and Tantasawat PA, unpublished results). In view of these results, it can be concluded that 'NY65.0550.04' is a good source of resistance to both downy mildew and anthracnose. RGA-SSCP markers associated with downy mildew and anthracnose resistance and revealed in this study may be useful in future grapevine breeding programs using 'NY65.0550.04' as a resistance source. However, the putative associations between these RGA-SSCP markers and resistance need to be verified with larger segregating populations before their subsequent use in future marker-assisted breeding programs.

\section{ACKNOWLEDGMENTS}

This work was supported by the Higher Education Research Promotion and National Research University Project of Thailand, Office of the Higher Education Commission, the Center of Excellence on Agricultural Biotechnology, Science and Technology Postgraduate Education and Research Development Office, Office of the Higher Education Commission, Ministry of Education (AG-BIO/PERDO-CHE), and grants from the Suranaree University of Technology, Thailand. We are very grateful to Dr. Bruce I. Reisch for providing potentially resistant hybrid cuttings.

\section{REFERENCES}

Abdurakhmonov IY and Abdukarimov A (2008). Application of association mapping to understanding the genetic diversity of plant germplasm resources. Int. J. Plant Genomics 2008: 574927.

Adam-Blondon A-F, Martinez-Zapater J-M and Kole C (2011). Genetics, Genomics, and Breeding of Grapes. Science Publishers, Enfield.

Bandyopadhyay T (2011). Molecular marker technology in genetic improvement of tea. Int. J. Plant Breed. Genet. 5: 23-33.

Brown MV and Moore JN (1999). Inheritance of downy mildew resistance in table grapes. J. Am. Soc. Hortic. Sci. 124: 262-267.

CAB International (2000). Crop Protection Compendium. CAB International, Wallingford, UK.

Cai QQ and Touitou I (1993). Excess PCR primers may dramatically affect SSCP efficiency. Nucleic Acids Res. 21: 3909-3910.

Collard BC and Mackill DJ (2008). Marker-assisted selection: an approach for precision plant breeding in the twenty-first century. Philos. Trans. R. Soc. Lond. B Biol. Sci. 363: 557-572.

Delmotte F, Chen WJ, Richard-Cervera S, Greif C, et al. (2006). Microsatellite DNA markers for Plasmopara viticola, the causal agent of downy mildew of grapes. Mol. Ecol. Notes 6: 379-381.

Diaz A, Fergany M, Formisano G, Ziarsolo P, et al. (2011). A consensus linkage map for molecular markers and quantitative trait loci associated with economically important traits in melon (Cucumis melo L.). BMC Plant Biol. 11: 111.

Immanuel SC, Pothiraj N, Thiyagarajan K, Bharathi M, et al. (2011). Identification of microsatellite (SSR) and RAPD markers linked to rice blast disease resistance gene in rice (Oryza sativa L.). Afr. J. Biotechnol. 10: 3301-3321.

Kalivas A, Xanthopoulos F, Kehagia O and Tsaftaris AS (2011). Agronomic characterization, genetic diversity and association analysis of cotton cultivars using simple sequence repeat molecular markers. Genet. Mol. Res. 10: 208-217.

Kar PK, Srivastava PP, Awasthi AK and Urs SR (2008). Genetic variability and association of ISSR markers with some biochemical traits in mulberry (Morus spp.) genetic resources available in India. Tree Genet. Genomes 4: 75-83.

Lefebvre V and Chèvre AM (1995). Tools for marking plant disease and pest resistance genes: a review. Agronomie 15: 3-19.

Levesque R and SPSS Inc. (2006). SPSS Programming and Data Management. 3rd edn. SPSS Institute, Somers.

Louime C, Lu J, Onokpise O, Vasanthaiah HKN, et al. (2011). Resistance to Elsinoe ampelina and expression of related resistant genes in Vitis rotundifolia michx. Int. J. Mol. Sci. 12: 3473-3488.

Mahanil S (2007). Inheritance and cloning of candidate resistance gene analogs (RGAs) for downy mildew in grapevine 
(Vitis spp.). Doctoral thesis, Suranaree University of Technology, Nakhon Ratchasima.

Mahanil S, Reisch BI, Owens CL, Thipyapong P, et al. (2007). Resistance gene analogs from Vitis cinerea, Vitis rupestris, and Vitis hybrid Horizon. Am. J. Enol. Vitic. 58: 484-493.

Milad SI, Wahba LE and Barakat MN (2011). Identification of RAPD and ISSR markers associated with flag leaf senescence under water-stressed conditions in wheat (Triticum aestivum L.). Aust. J. Crop Sci. 5: 337-343.

Mortensen JA (1981). Sources and inheritance of resistance to anthracnose in Vitis. J. Hered. 72: 423-426.

Nisar M and Ghafoor A (2011). Linkage of a RAPD marker with powdery mildew resistance er-1 gene in Pisum sativum L. Russ. J. Genet. 47: 300-304.

Obert DE, Skinner DZ and Stuteville DL (2000). Association of AFLP markers with downy mildew resistance in autotetraploid alfalfa. Mol. Breed. 6: 287-294.

Owens CL (2003). SNP detection and genotyping in Vitis. Acta Hort. 603: 139-140.

Poolsawat O (2010). Pathogen Diversity, Resistance and Development of Molecular Markers for Resistance Genes to Sphaceloma ampelinum, the Causal Agent of Grape Scab (Anthracnose). Doctoral thesis, Suranaree University of Technology, Nakhon Ratchasima.

Poolsawat O, Tharapreuksapong A, Wongkaew S and Tantasawat P (2009). Cultural characteristics of Sphaceloma ampelinum, causal pathogen of grape anthracnose on different media. Suranaree J. Sci. Technol. 16: 149-157.

Poolsawat O, Tharapreuksapong A, Wongkaew S, Reisch BI, et al. (2010). Genetic diversity and pathogenicity analysis of Sphaceloma ampelinum causing grape anthracnose in Thailand. J. Phytopathol. 158: 837-840.

Poolsawat O, Tharapreuksapong A, Wongkaew S, Chaowiset W, et al. (2012). Laboratory and field evaluations of resistance to Sphaceloma ampelinum causing anthracnose in grapevine. Australasian Plant Pathol. 41: 263-269.

Pradeep AR, Jingade AH and Urs RS (2007). Molecular markers for biomass traits: association, interaction and genetic divergence in silkworm Bombyx mori. Biomark. Insights 2: 197-217.

Reisch BI and Pratt C (1996). Fruit Breeding, Volume II: Vine and Small Fruit Crops. John Wiley and Sons, New York.

Riaz S, Tenscher AC, Graziani R, Krivanek AF, et al. (2009). Using marker-assisted selection to breed Pierce's diseaseresistant grapes. Am. J. Enol. Vitic. 60: 199-207.

Riaz S, Tenscher AC, Ramming DW and Walker MA (2011). Using a limited mapping strategy to identify major QTLs for resistance to grapevine powdery mildew (Erysiphe necator) and their use in marker-assisted breeding. Theor. Appl. Genet. 122: 1059-1073.

Roy JK, Bandopadhyay R, Rustgi S, Balyan HS, et al. (2006). Association analysis of agronomically important traits using SSR, SAMPL and AFLP markers in bread wheat. Curr. Sci. 90: 683-689.

Ruan C-J, Li H and Mopper S (2009). Characterization and identification of ISSR markers associated with resistance to dried-shrink disease in sea buckthorn. Mol. Breed. 24: 255-268.

Sambrook J and Russell DW (2001). Molecular Cloning: A Laboratory Manual. Cold Spring Harbor Laboratory Press, New York.

Seehalak W, Moonsom S, Metheenukul P and Tantasawat P (2011). Isolation of resistance gene analogs from grapevine resistant and susceptible to downy mildew and anthracnose. Sci. Hortic. 128: 357-363.

Shalini KV, Manjunatha S, Lebrun P, Berger A, et al. (2007). Identification of molecular markers associated with mite resistance in coconut (Cocos nucifera L.). Genome 50: 35-42.

Sunnucks P, Wilson AC, Beheregaray LB, Zenger K, et al. (2000). SSCP is not so difficult: the application and utility of single-stranded conformation polymorphism in evolutionary biology and molecular ecology. Mol. Ecol. 9: 1699-1710.

Tharapreuksapong A, Poolsawat O, Jenweerawat S, Wongkaew S, et al. (2009). Molecular, morphological and pathogenicity characterization of Sphaceloma ampelinum isolates from Thailand. Acta Hort. 827: 611-618.

Tian L, Wang Y, Niu L and Tang D (2008). Breeding of disease-resistant seedless grapes using Chinese wild Vitis spp. I. In vitro embryo rescue and plant development. Sci. Hortic. 117: 136-141.

Virk PS, Ford-Lloyd BV, Jackson MT, Pooni HS, et al. (1996). Predicting quantitative variation within rice germplasm using molecular markers. Heredity 76: 296-304.

Wang X, Wang Y, Zhou P and Zhang X (2000). RAPD analysis of Vitis to anthracnose resistance gene. J. Agric. Biotechnol. 8: 361-364.

Wang X, Qiu X, Meng X and Yang L (2010). Preliminary study on polymorphism analysis of SpRunt-1 gene by PCRSSCP in Strongylocentrotus intermedius and its association with growth traits. Mol. Biol. Rep. 37: 411-415.

Wang Y, Wang X, Zhou P and Zheng X (2000). A RAPD marker linked to anthracnose resistance gene of wild grapes native to China. Acta Hortic. Sin. 27: 321-325.

Yu X, Bai G, Luo N, Chen Z, et al. (2011). Association of simple sequence repeat (SSR) markers with submergence tolerance in diverse populations of perennial ryegrass. Plant Sci. 180: 391-398.

Zhang J, Wang Y, Zhou P, Wang X, et al. (2001). RAPD marker of resistance gene to anthracnose in Chinese wild Vitis. J. Fruit Sci. 18: 68-71. 